\title{
Análise da interface padrão do Oxwall como plataforma de rede social
}

\author{
Review of Oxwall's default interface as a social network platform
}

\author{
Luís Henrique Lindner, Vania Ribas Ulbricht, Luiz Antônio Moro Palazzo
}

Redes Sociais,

Interfaces, Usabilidade, Sociabilidade, Oxwall
1 www.oxwall.org

Social networks, Interfaces, Usability, Sociability, Oxwall

\begin{abstract}
As redes sociais tem se destacado, entre outros, por incentivar o usuário a produzir conteúdo. Ambientes corporativos e acadêmicos têm buscado explorar esse potencial, criando redes sociais temáticas ou corporativas, onde pessoas e grupos se comunicam de forma similar as redes sociais massivas, mas de forma independente. Uma das plataformas livres mais utilizadas para construção destas redes sociais é o Oxwall'. Assim, este artigo apresenta a análise da interface padrão do Oxwall com base no framework Reader-to-Leader, que considera aspectos de usabilidade e sociabilidade para promover a participação do usuário. Como a sociabilidade envolve ações de gestão da rede, ela não é analisada neste artigo. A avaliação da usabilidade, por sua vez, aponta que a interface padrão da plataforma contém elementos que incentivam a participação dos usuários nos níveis de leitor e contribuidor. Contudo, carece de fatores que estimulem usuários a atingirem níveis mais altos de interação e produção de conteúdo, como os colaboradores e líderes.
\end{abstract}

Social networks have been emphasized by encouraging users to produce content. Corporate and academic environments have pursued to exploit this potential by creating thematic or corporate social networks, where people and groups communicate in a similar way to the massive social networks, but independently. One of the free platforms most used for construction of these social networks is Oxwall. Thus, this article presents an analysis of the default interface of Oxwall based on the "Reader-toLeader" framework, which considers both aspects of usability and sociability to promote user participation. As the sociability depends on specific network management, it is not analysed. The usability evaluation, however, shows that the platform interface contains elements that encourage the participation of users in the levels of reader and contributor. However, it lacks of factors that stimulate users to achieve higher levels of interaction and content production, as collaborators and leaders.

\section{Introdução}

O fenômeno das Redes Sociais tem se consolidado como forma de comunicação, colaboração e trabalho online. Segundo dados do NetView, uma publicação do IBOPE Media (IBOPE, 2013), 86\% dos internautas ativos são usuários de redes sociais, o que representa 
um crescimento de $15 \%$ em relação à 2012. Não obstante, observa-se que o mercado logo demonstrou interesse pela nova mídia, explorando novas formas de publicidade e relacionamento com seus consumidores.

O foco nas redes sociais, todavia, tem ultrapassado as fronteiras do mercado e suas vantagens tem sido exploradas também em ambientes de trabalho e educação, apesar de ainda serem incipientes. Segundo Howard (2010), as redes sociais massivas, como Facebook, são ideais para socialização, mas dificultam trabalhos que exigem especialização e foco, como a educação. A diversidade de temas em uma rede social também é apontada com fator crítico, pois os usuários tendem a se perder na navegação, interessados pelos diversos temas. Embora haja uma sensação de facilidade no acesso à informação, a construção de conhecimentos de forma colaborativa on-line se torna prejudicada, visto que esse tipo de atividade exige especialização e concentração (ALbors et al, 2008). Nesse cenário surgem, inicialmente, as comunidades online para discussão de temas específicos e mais recentemente, as redes sociais temáticas. As Redes Sociais Temáticas (RST) possuem os mesmos recursos de uma rede social, mas são construídas em torno de um tema central, foco dos membros da rede.

Para garantir a interação e a colaboração dos usuários, estas redes contam com diversos recursos como fóruns, chats, feeds de notícias, galerias, grupos etc. Contudo, os recursos isolados não estimulam a participação sem que haja uma boa interface. A interface é essencial para o usuário, desde o acesso à informação até a possibilidade de intervir com conteúdo próprio, colaborar e controlar. Nesse sentido, questiona-se: como a interface pode promover a interação do usuário em redes sociais?

\section{Redes sociais}

O conceito de rede social antecede o surgimento das tecnologias atuais, podendo ser compreendido por atores - nodos - membros que estão conectados de diversas formas, dependendo do tipo de relação adotado (ZHANG, 2010). No entanto, com estabelecimento da internet, o conceito de rede social tem se mesclado com os próprios sites de redes sociais.

Sites de redes sociais, para Kaplan e Haenlein (2010), são aplicativos que permitem ao usuário se conectar através da criação de um perfil de informações pessoais, convidar amigos e colegas para ter acesso a esse perfil, assim como enviar mensagens instantâneas entre si.

Boyd e Ellison (2007), apontam três características básicas que definem sites de redes sociais. Segundo os autores, trata-se de serviços baseados na web que permitem aos indivíduos:

1. Construir um perfil público ou semi-público; 
2. Criar uma lista de conexões; e

3. Ver e percorrer a sua lista de conexões e aquelas feitas por outros dentro do sistema. A natureza e nomenclatura dessas conexões podem variar de site para site.

Segundo Boyd e Ellison (2007), os sites de redes sociais tem sua origem em 1997 com o SixDegrees, um site em que as pessoas adicionavam os amigos e podiam ver outras listas de amigos, além de trocar mensagens. Contudo, o ponto da virada foi em 2003, quando dezenas de serviços surgiram, iniciando o fenômeno das redes sociais.

As redes sociais tem sido foco de diversas organizações, por diferentes aspectos. Howard (2010) destaca alguns benefícios, como:

- Reforçar e manter o seu "capital intelectual”;

- Aumentar a criatividade e a "fertilização cruzada";

- Melhorar os processos de tomada de decisão com "comunidades epistêmicas";

- Proporcionar uma maior interação de qualidade com a sua organização;

- Reduzir os custos de viagem e resolução de problemas "just in time";

- Achatamento das hierarquias organizacionais.

As redes sociais, contudo, são focadas no indivíduo e suas relações sociais (um-pra-um). Para Howard (2010), redes sociais são ideais para compartilhar informações, mas seus laços secundários, em geral, são mais fracos, não sendo eficazes em atividades que exigem cooperação e colaboração.

Albors et al (2008) reforçam essa ideia quando afirmam que atividades colaborativas exigem um grau de especialização, portanto, o excesso de informação das redes sociais massivas pode ser prejudicial. Para que uma atividade colaborativa seja eficaz, o grau de conectividade da informação deve ser tão alto quanto o grau de conectividade social (BERNARD et al 2006 apud ALBORS et al, 2008). Ou seja, além dos laços sociais, há necessidade de uma conexão informacional entre as diferentes pessoas, um tema central. Nesse contexto, está implícito o conceito de comunidade de prática, em que a identidade do grupo é definida pelo domínio de interesse compartilhado e pela aprendizagem situada (WENGER, 2000).

Para Wenger (1998), a ideia de comunidade não implica em que o grupo seja homogêneo, de um mesmo grupo social, ou ainda que esteja no mesmo espaço físico. Mas sim, que exista um vínculo entre as pessoas do grupo pelas tarefas que são executadas e pelos recursos que compartilham entre si. Estes recursos, por sua vez, devem ser reconhecidos e utilizados pelos participantes (prática). A diferença em relação ao conceito de rede social reside no fato da comunidade não exigir que os usuários tenham listas de conexões visíveis, o que caracteriza a ideia de rede. 
Seguindo este caminho, um tipo particular de rede social, denominada temática, parece ser especialmente adequada para reunir pessoas acerca de um domínio de conhecimento, formando uma ou mais comunidades e representando as conexões sociais por meio das listas de amigos/colegas.

\section{Redes Sociais Temáticas}

De acordo com Palazzo et al (2014), as Redes Sociais Temáticas (RST) possuem todos os recursos de uma rede social convencional, como Facebook: perfil do usuário, mensagens, mural, chat, listas de amigos, repositório, entre outros. Contudo, em uma RST, a comunidade tem controle sobre os recursos que irá utilizar e suas configurações. Além disso, também permite a personalização da interface e da experiência do usuário de acordo com as políticas específicas da comunidade.

A RST é formada a partir de quatro entidades (PALAzzo et al, 2014):

1. Pessoas: os usuários da rede (nodos), cuja atividade consiste em estudar, pesquisar, coletar e submeter conteúdo relevante para o desenvolvimento coletivo do tema (a conexão entre os nodos). As pessoas possuem um perfil - uma representação digital de si próprias - que, além persona, inclui a presença na rede, os perfis de atividade e o grafo social. Com seu perfil, a pessoas tem acesso à interface da rede e a um grande número de ferramentas de comunicação, pesquisa, informação e colaboração;

2. Infraestrutura: tudo o que suporta o funcionamento da RST - servidores, estações de trabalho, dispositivos móveis como tablets e smartphones, a infraestrutura de rede, protocolos e programas;

3. Aplicativo: é o programa principal da RST que, além de prover a interface entre os membros da rede, organiza a informação, disponibiliza todos os serviços, recursos e aplicativos típicos de uma rede social e coloca os participantes em contato seletivamente nas formas privada ou pública, síncrona ou assíncrona.

4. Tema: é o objeto de conhecimento que se deseja estudar ou desenvolver e que conecta as pessoas na rede.

Para construção de RSTs podem ser utilizadas Social Networking Platforms - plataformas livres ou pagas com diversos recursos e plugins (ISMAIL, 2013). Segundo ranking do CMS Critic (2014), um

www.oxwall.org

www.boonex.com

www.elgg.org

www.buddypress.org portal especializado na análise destas plataformas, entre as opções open source encontram-se Oxwall ${ }^{2}$, Dolphin ${ }^{3}$, Elgg ${ }^{4}$, BuddyPress ${ }^{5}$. Destas, o Oxwall recebe a melhor avaliação - quatro de cinco estrelas - impulsionado pela facilidade de uso e de instalação. Apesar de serem 
independentes, as interfaces destas redes buscam referências nas redes sociais massivas com objetivo de promover a colaboração entres os membros. Esta familiaridade deu ao Oxwall, em 2012, o título de melhor plataforma por meio de votos dos usuários no Critics' Choice CMS Awards (2014).

O sistema funciona a partir de uma arquitetura de plugins, o que possibilita incluir diversas funcionalidades. Contudo, quando se analisa o pacote default da plataforma - os recursos que vem no conjunto inicial de instalação, o Oxwall se destaca. Além disso, ele se destaca pela facilidade de instalação e pela interface amigável (OXWALL, 2013).

A plataforma conta com uma interface padrão e algumas funcionalidades nativas, como:

- listas de amigos;

- grupos;

- mural para compartilhamento de textos, fotos e vídeos;

- blogs;

- fóruns;

- wiki;

- eventos;

- comentários;

- categorias/tags;

- customização do perfil; e

- opções de privacidade.

\section{Metodologia para análise da interface}

A evolução tecnológica permitiu avanços na produção de interfaces cada vez mais interativas e voltadas para o usuários. Além disso, a popularização da internet e dos dispositivos móveis tem possibilitado o aumento de atividades colaborativas na chamada Web 2.o (Iворе, 2013).

Sob a perspectiva da interface, passa-se a exigir mídias que forneçam não apenas o acesso às informações, mas a interação com elas, contribuindo e modificando-as. Neste cenário, Preece e Schneiderman (2009) observaram que há diferentes possibilidades de interação em sites colaborativos e que nem todos os usuários contribuem ou lideram as discussões, o que os levou a uma classificação dos usuários em quatro níveis.

Inicialmente os usuários interagem em um site como leitores, entrando em algum grupo de discussão, lendo posts de blogs, vendo imagens e vídeos. Muitos destes leitores continuam nesse estágio, mas alguns retornam e passam a interferir nos conteúdos, corrigindo alguma palavra, avaliando algum conteúdo e comentando, tornando-se então contribuidores. Destes, uma parte acaba se envolvendo mais e passa a contribuir com mais frequência, atingindo o nível que os 
autores consideram como colaboradores. Por fim, com passar do tempo e a manutenção das atividades, os colaboradores podem se tornar líderes, como referência no tema em questão, dada a sua importância e sua participação na rede (PREECE; SCHNEIDERMAN, 2009).

Com base nesses diferentes perfis de uso, Preece e Schneiderman (2009) propõem o framework "Reader-to-Leader" (de leitor a líder). A ideia é que se promova a evolução do usuário dentro do site social,

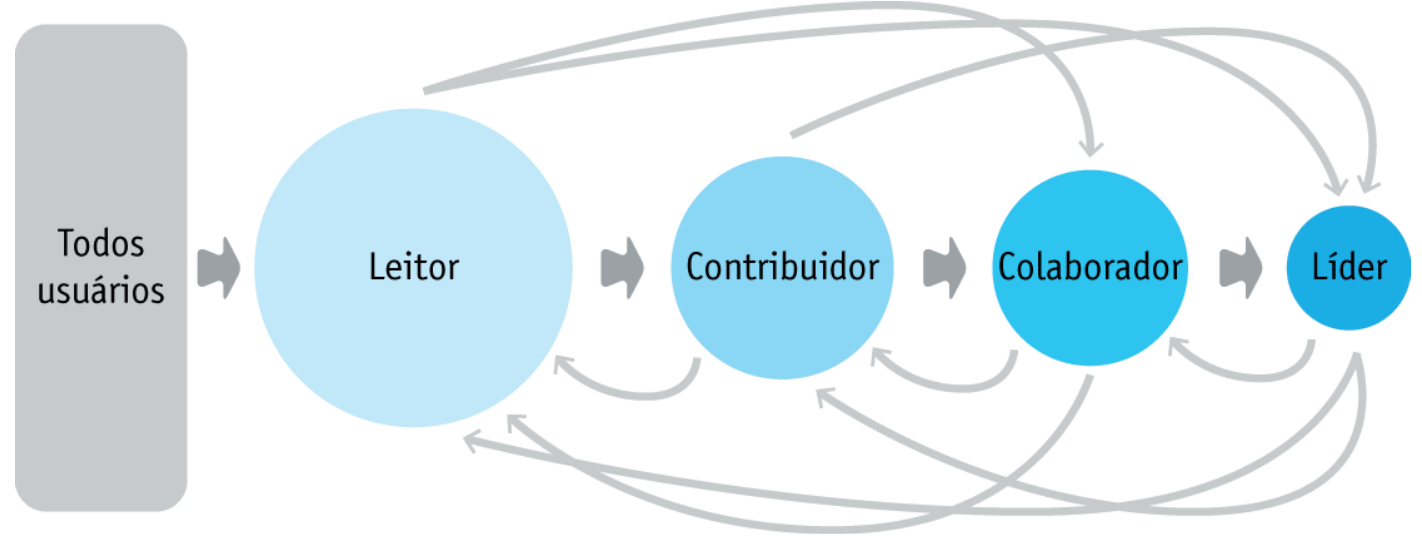

Figura 1 Framework Reader-to-Leader

(Fonte: Adaptado de Preece e Schneiderman, 2009, p. 16)

para que mais pessoas passem a colaborar, enriquecendo a construção do conhecimento na rede.

Este framework, apoiado por extensas referências a trabalhos de pesquisas comportamentais, foi projetado para ajudar investigadores, designers e gerentes a entenderem o que motiva a participação social mediada pela tecnologia. Permite aprimorar o design da interface e promover a interação social em diferentes organizações (PREECE; SCHNEIDERMAN, 2009).

Segundo os autores, cada nível de interação deve ser analisado em detalhes pois implica em uma visão diferente dos elementos da interface. Assim, além de estabelecer critérios de usabilidade para cada nível, Preece e Schneiderman (2009) destacam a importância de se analisar também como pode ser trabalhada a sociabilidade. A seguir são apresentados os critérios propostos para cada perfil de usuário.

\subsection{Leitor}

O usuário em nível leitor navega basicamente realizando leituras e buscas. Nesse sentido, os requisitos aplicáveis são os clássicos da Web 1.0 - a pessoa não contribui no conteúdo, apenas o acessa, conforme apresentado no Quadro 1. 
Quadro 1 Fatores de Usabilidade e Sociabilidade que influenciam a leitura (Preece e Schneiderman, 2009, p. 18 (tradução nossa))

\begin{tabular}{|l|l|}
\hline Usabilidade & Sociabilidade \\
\hline $\begin{array}{l}\text { Conteúdo relevante e interessante, } \\
\text { apresentado de forma atrativa em layouts } \\
\text { organizados }\end{array}$ & $\begin{array}{l}\text { Incentivo dos amigos, família, autoridades, } \\
\text { publicidade }\end{array}$ \\
\hline $\begin{array}{l}\text { Conteúdo atualizado com frequência com } \\
\text { destaques para incentivar o retorno dos } \\
\text { visitantes }\end{array}$ & $\begin{array}{l}\text { Visibilidade abrangente: online, impressa, } \\
\text { televisiva ou em outras mídias }\end{array}$ \\
\hline $\begin{array}{l}\text { Suporte para novatos por meio de tutoriais } \\
\text { animados, FAQs, ajuda, orientadores, contatos }\end{array}$ & $\begin{array}{l}\text { Normas ou políticas claras e fáceis de } \\
\text { serem entendidas }\end{array}$ \\
\hline $\begin{array}{l}\text { Navegação clara de modo que os usuários } \\
\text { sintam controle sobre a interação }\end{array}$ & $\begin{array}{l}\text { Sensação de pertencimento baseada no } \\
\text { reconhecimento de pessoas e atividades } \\
\text { conhecidas }\end{array}$ \\
\hline $\begin{array}{l}\text { Usabilidade universal para suportar novatos/ } \\
\text { avançados, telas pequenas/grande, conexões } \\
\text { lentas/rápidas, diversas línguas e usuários } \\
\text { com algum tipo de deficiência }\end{array}$ & Líderes carismáticos e visionários \\
\hline $\begin{array}{l}\text { Elementos de design de interface que } \\
\text { promovam leitura, navegação, busca e } \\
\text { compartilhamento }\end{array}$ & Segurança e privacidade \\
\hline
\end{tabular}

\subsection{Contribuidor}

O usuário contribuidor é aquele que por curiosidade e interesse encontra formas de interagir com a comunidade, seja avaliando ou comentando um assunto. No Quadro 2 são apresentados os fatores que influenciam a atividade de colaboração.

Quadro 2 Fatores de Usabilidade e Sociabilidade que influenciam a contribuição (Preece e Schneiderman, 2009, p. 21 (tradução nossa))

\begin{tabular}{|l|l|}
\hline Usabilidade & Sociabilidade \\
\hline $\begin{array}{l}\text { Entrada facilitada para contribuições simples } \\
\text { (por ex.: sem login) }\end{array}$ & $\begin{array}{l}\text { Suporte à participação periférica de modo } \\
\text { que leitores possam passar para o nível de } \\
\text { contribuição }\end{array}$ \\
\hline $\begin{array}{l}\text { Interface ampla, permitindo contribuições } \\
\text { mais longas e frequentes }\end{array}$ & $\begin{array}{l}\text { Oportunidade de construir uma reputação } \\
\text { ao longo do tempo durante a execução de } \\
\text { tarefas gratificantes }\end{array}$ \\
\hline $\begin{array}{l}\text { Visibilidade para as contribuições dos usuários, } \\
\text { frequência de visualizações ao longo do tempo }\end{array}$ & $\begin{array}{l}\text { Reconhecimento dos contribuidores em } \\
\text { maior qualidade e maior quantidade }\end{array}$ \\
\hline $\begin{array}{l}\text { Visibilidade das avaliações e comentários dos } \\
\text { membros da comunidade }\end{array}$ & $\begin{array}{l}\text { Reconhecimento de uma expertise } \\
\text { específica da pessoa }\end{array}$ \\
\hline $\begin{array}{l}\text { Ferramentas para desfazer práticas } \\
\text { de vandalismo, limitar usuários mal- } \\
\text { intencionados, controlar a pornografia }\end{array}$ & $\begin{array}{l}\text { Políticas e normas sobre contribuições } \\
\text { adequadas }\end{array}$ \\
\hline
\end{tabular}

\subsection{Colaborador}

O colaborador possui um perfil de maior envolvimento com a comunidade, se relacionando com mais frequência com outros membros, em diferentes grupos. Nesse sentido, o Quadro 3 apresenta fatores que intensificam esse envolvimento. 
Quadro 3 Fatores de Usabilidade e Sociabilidade que influenciam a colaboração (Preece e Schneiderman, 2009, p. 23 (tradução nossa))

\begin{tabular}{|l|l|}
\hline Usabilidade & Sociabilidade \\
\hline $\begin{array}{l}\text { Formas de localizar indivíduos relevantes e } \\
\text { competentes para formar colaborações }\end{array}$ & $\begin{array}{l}\text { Uma atmosfera de empatia e confiança } \\
\text { que favorece o pertencimento à } \\
\text { comunidade e disposição para trabalhar } \\
\text { em grupos para produzir algo maior }\end{array}$ \\
\hline $\begin{array}{l}\text { Ferramentas colaborativas: comunicação } \\
\text { entre grupos, agenda de projetos, tarefas, } \\
\text { compartilhamento de trabalhos, assistência }\end{array}$ & $\begin{array}{l}\text { Altruísmo: o desejo de apoiar a } \\
\text { comunidade, o desejo de retribuir, ser } \\
\text { recíproco }\end{array}$ \\
\hline $\begin{array}{l}\text { Reconhecimento público e premiações, por } \\
\text { ex.: autoria, citações, links, agradecimentos }\end{array}$ & $\begin{array}{l}\text { O desejo de desenvolver uma reputação } \\
\text { própria e para seus colaboradores, seu } \\
\text { grupo ou comunidade; necessidade de } \\
\text { desenvolver e manter seu status dentro } \\
\text { do grupo }\end{array}$ \\
\hline $\begin{array}{l}\text { Formas de resolver diferenças (por ex. } \\
\text { votações), mediar disputas e lidar com } \\
\text { colaboradores inúteis (que atrapalham) }\end{array}$ & $\begin{array}{l}\text { Respeito pelo status de alguém dentro de } \\
\text { uma comunidade }\end{array}$ \\
\hline
\end{tabular}

\subsection{Líder}

De acordo com Preece e Schneiderman (2009), o líder se responsabiliza de certa forma pela rede, sintetizando ideias, orientando os iniciantes, definindo políticas e interferindo em discussões. A liderança pode ser informal - obtida por meio da reputação do usuário, ou definida previamente entre os administradores da rede. O Quadro 4 indica fatores que possibilitam a atividade de liderança.

Quadro 4 Fatores de Usabilidade e Sociabilidade que influenciam a liderança (Preece e Schneiderman, 2009, p. 24 (tradução nossa))

\begin{tabular}{|l|l|}
\hline Usabilidade & Sociabilidade \\
\hline $\begin{array}{l}\text { Líderes recebem mais visibilidade e seus } \\
\text { esforços são destacados, às vezes com } \\
\text { narrativas históricas, homenagens ou prêmios }\end{array}$ & $\begin{array}{l}\text { A liderança é valorizada e recebe uma } \\
\text { posição de honra que deverá atender às } \\
\text { expectativas }\end{array}$ \\
\hline $\begin{array}{l}\text { Líderes recebem poderes especiais, por ex. } \\
\text { para promover pautas, utilizar recursos, ou } \\
\text { limitar usuários mal-intencionados }\end{array}$ & $\begin{array}{l}\text { É oferecido respeito para ajudar os outros } \\
\text { a lidar com os problemas }\end{array}$ \\
\hline $\begin{array}{l}\text { Esforços de orientação são visivelmente } \\
\text { enaltecidos, por exemplo, com comentários de } \\
\text { orientandos }\end{array}$ & Orientadores são cultivados e encorajados \\
\hline
\end{tabular}

Cabe ressaltar que os usuários podem assumir diferentes perfis, dependendo do grupo ou tema tratado na rede. Assim como, os fatores que influenciam as atividades de leitura, continuam existindo para os níveis subsequentes. A seguir é apresentado um estudo analítico de interface com base nos fatores supracitados. 


\section{Estudo Analítico}

A interface a ser analisada foi desenvolvida pela equipe do software livre para criação de redes sociais, Oxwall, na versão 1.5. Para análise, é utilizado o framework Reader-to-Leader, proposto por Preece em Schneiderman (2009). Conforme apresentado, o framework considera fatores nas dimensões de usabilidade e sociabilidade, em quatro níveis de engajamento do usuário com a rede. Segundo os autores, os fatores de usabilidade são de responsabilidade do designer, enquanto que a sociabilidade deve ser promovida pelo gestor da rede. Nesse sentido, não são avaliados os fatores específicos de sociabilidade neste artigo, que foca na interface gráfica.

\subsection{Descrição da interface}

A interface analisada apresenta três áreas principais: cabeçalho, menu horizontal e área de conteúdo (Figura 2). O cabeçalho é fixo e personalizável por meio de imagem, frequentemente utilizado para identificação da rede. O menu, também fixo, apresenta as funcionalidades ativas, como: membros, fotos, vídeos, blogs, eventos, grupos, fórum e links, além de acesso à página principal e painel pessoal - main e dashboard.

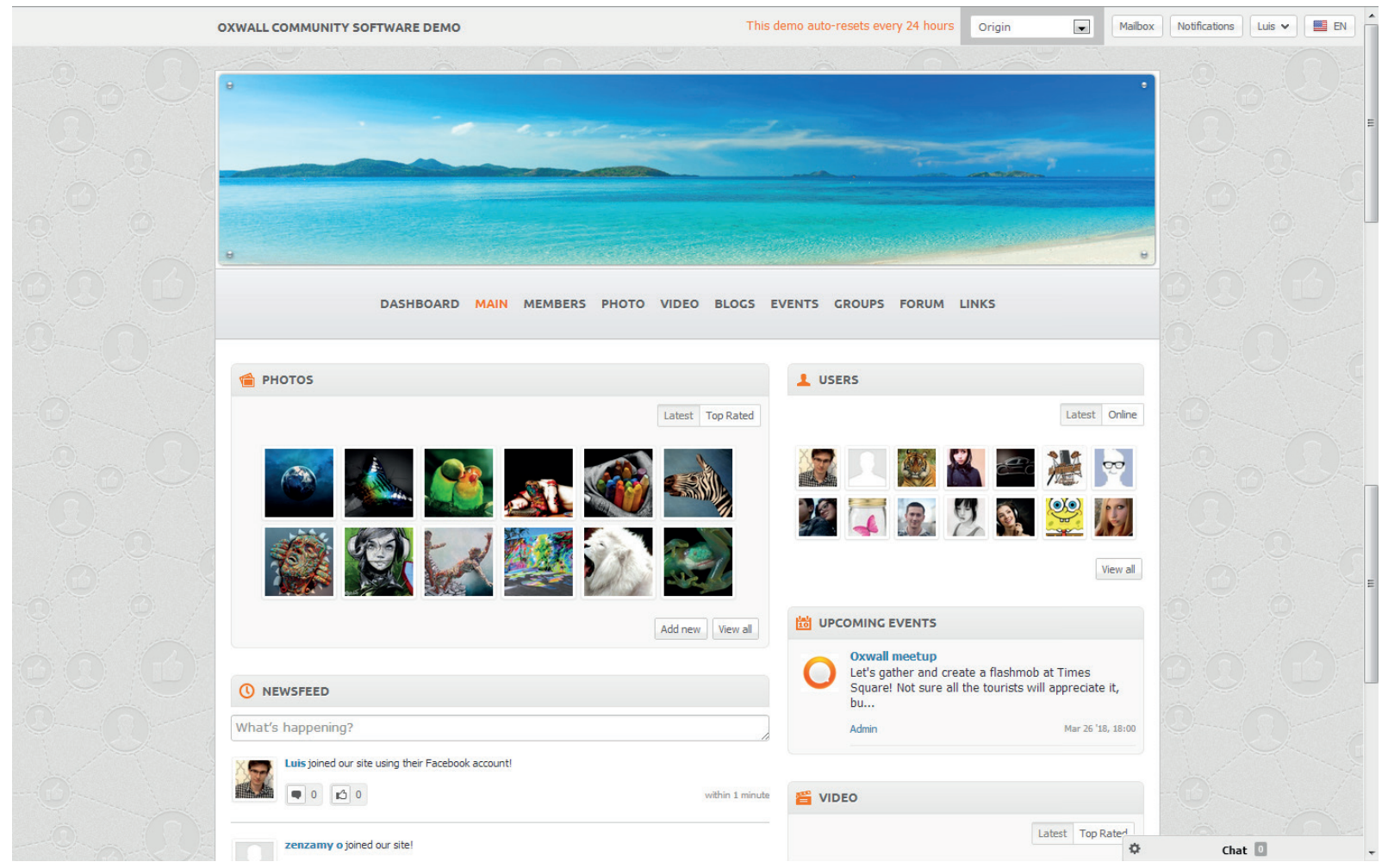

Figura 2 Página principal da interface padrão do Oxwall

(Fonte: Demonstração Oxwall (2013)) 
A área de conteúdo é separada em duas colunas com blocos cambiáveis, definidos pelo administrador da rede para página principal - main. Na figura anterior, observa-se os blocos Photos, Users, Newsfeed, Upcoming Events e Video. Já no painel pessoal - dashboard (Figura 3), o usuário pode personalizar a ordem dos blocos, incluindo e excluindo-os. Nesse sentido, observa-se na figura a seguir o botão Customize this page, que indica essa possibilidade. A edição é feita com recurso drag and drop para reposicionar os blocos e por meio dos ícones de configuração e exclusão (Figura 4).

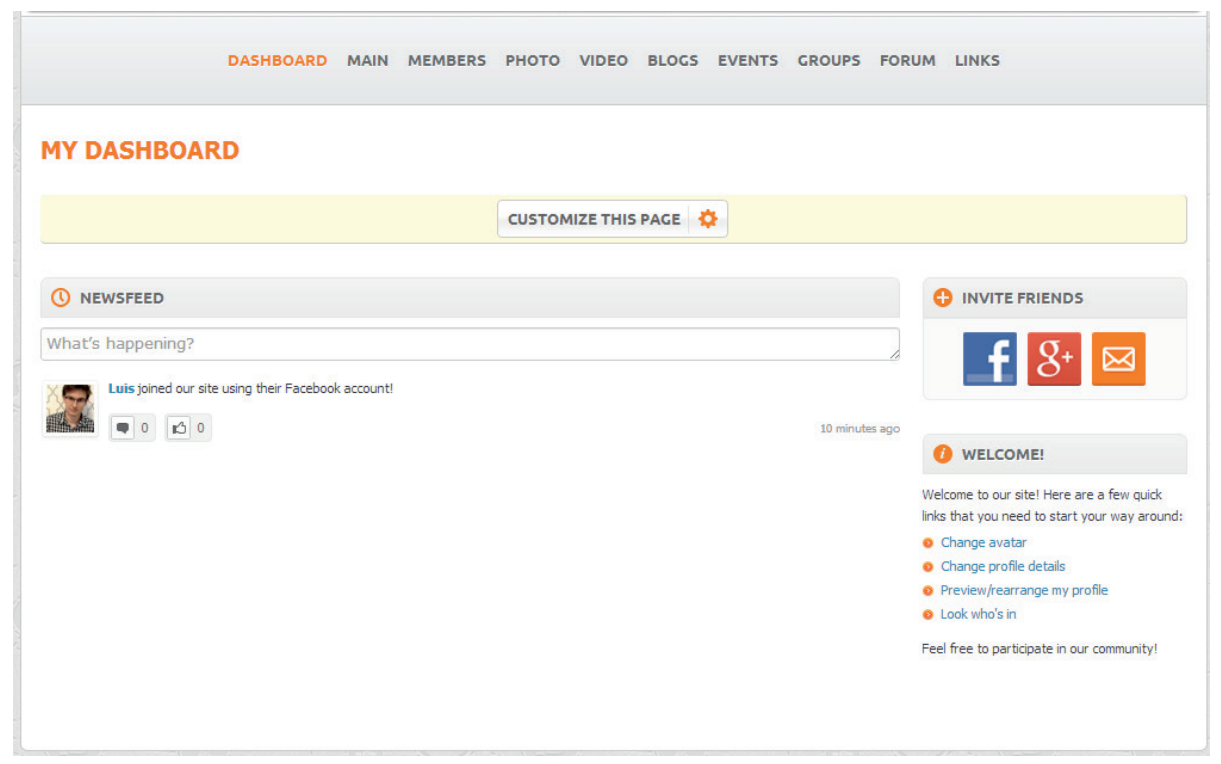

Figura 3 Painel pessoal customizável - dashboard (Fonte: Demonstração Oxwall (2013))

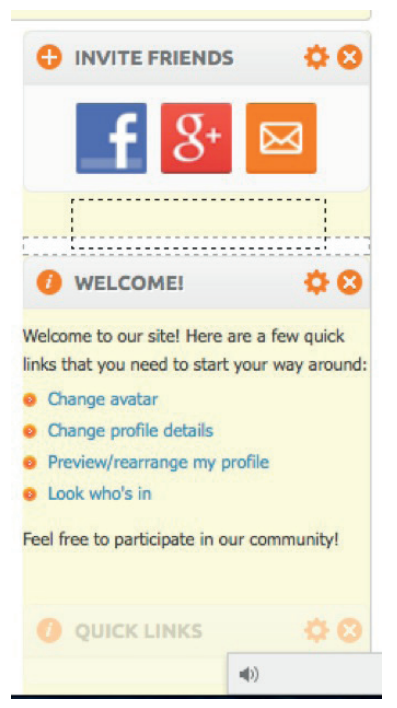

Figura 4 Detalhe do recurso de edição de blocos (Fonte: Demonstração Oxwall (2013)) 
As demais páginas seguem um layout específico, geralmente utilizando navegação por abas e uma coluna principal. A página de eventos, por exemplo, possui as seguintes abas: Chegando, Anteriores (Passados), Meus eventos e Convites. À direita, encontra-se um botão para adicionar novos eventos. Na coluna de conteúdo, os eventos aparacem em forma de link, com breve descrição, criador e data (Figura 5).

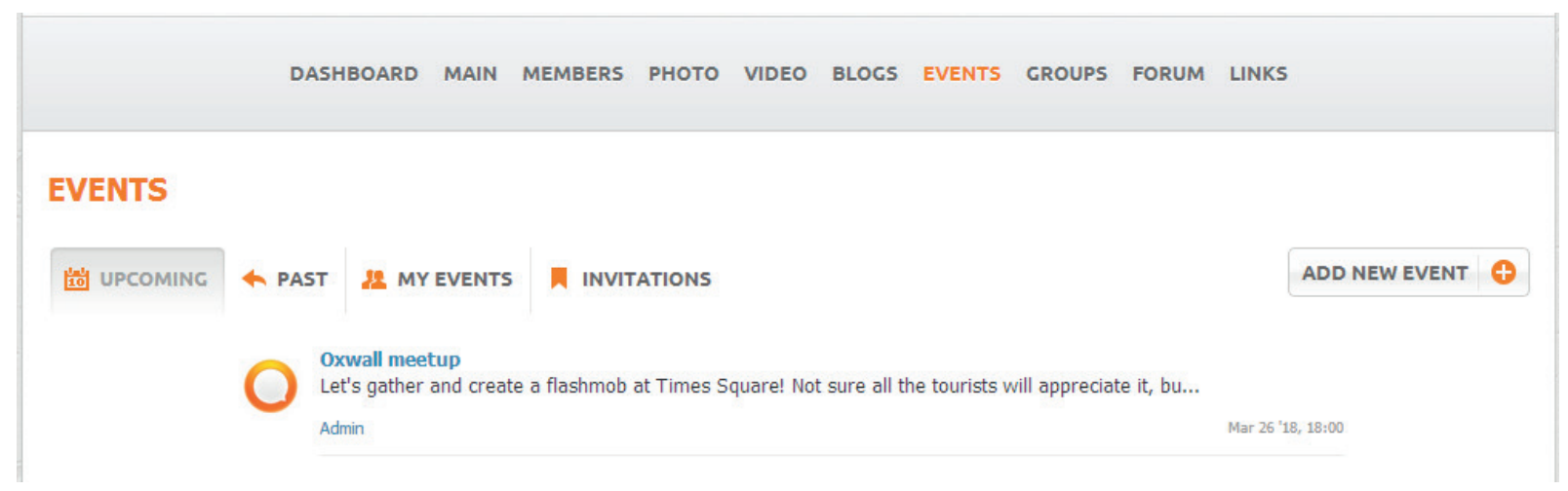

Figura 5 Página de eventos (Fonte: Demonstração Oxwall (2013))

Visualmente a interface apresenta um layout claro, com uso predominante de branco e cinza. Utiliza-se ainda a cor laranja para títulos, localização e ícones e a cor azul para hiperlinks em geral. Todos os blocos apresentam cabeçalho em fundo cinza, similar ao menu. Alguns blocos possuem delimitação de área com um leve contorno cinza e fundo cinza claro, enquanto outros apresentam fundo branco e ausência de contorno (Figura 6).

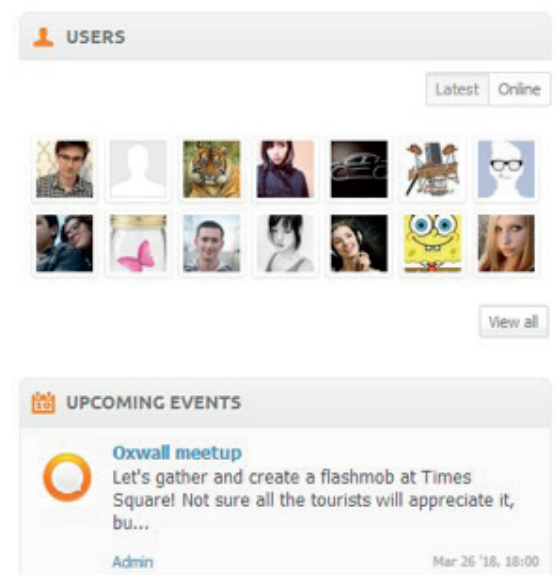

Figura 6 Detalhe visual dos blocos (Fonte: Demonstração Oxwall (2013))

\subsection{Análise da interface}

A análise tomou como base os 18 fatores que influenciam a usabilidade em redes sociais, sugerido por Preece e Schneiderman (2009). Inicialmente foram levantadas observações para cada critério. Em seguida, cada um foi avaliado seguindo uma escala Likert - 
comumente utilizada para quantificar indicadores (CRESWELL, 2003). A escala considerou três níveis: Não atende, Atende parcialmente, Atende totalmente. A análise é apresentada no Quadro 5 e na Figura 7.

Quadro 5 - Análise da usabilidade segundo framework Reader-to-Leader

\begin{tabular}{|c|c|c|}
\hline & Critério de usabilidade & Observações \\
\hline 1 & $\begin{array}{l}\text { Conteúdo relevante e interessante, apresentado de } \\
\text { forma atrativa em layouts organizados }\end{array}$ & $\begin{array}{l}\text { As informações em blocos e o visual leve contribuem } \\
\text { para o acesso ao conteúdo }\end{array}$ \\
\hline 2 & $\begin{array}{l}\text { Conteúdo atualizado com frequência com destaques } \\
\text { para incentivar o retorno dos visitantes }\end{array}$ & $\begin{array}{l}\text { O newsfeed e o fórum priorizam as atualizações } \\
\text { recentes, mas não há como destacar publicações } \\
\text { específicas }\end{array}$ \\
\hline 3 & $\begin{array}{l}\text { Suporte para novatos por meio de tutoriais animados, } \\
\text { FAQs, ajuda, orientadores, contatos }\end{array}$ & A rede conta com textos de ajuda personalizáveis. \\
\hline 4 & $\begin{array}{l}\text { Navegação clara de modo que os usuários sintam } \\
\text { controle sobre a interação }\end{array}$ & $\begin{array}{l}\text { A estrutura é simples e permite a personalização da } \\
\text { página pessoal. }\end{array}$ \\
\hline 5 & $\begin{array}{l}\text { Usabilidade universal para suportar novatos/ } \\
\text { avançados, telas pequenas/grande, conexões lentas/ } \\
\text { rápidas, diversas línguas e usuários com algum tipo de } \\
\text { deficiência }\end{array}$ & $\begin{array}{l}\text { A estrutura simples e modular torna a interface } \\
\text { adaptável aos diferentes suportes, mas carece de } \\
\text { descrições textuais para algumas imagens e ícones. }\end{array}$ \\
\hline 6 & $\begin{array}{l}\text { Elementos de design de interface que promovam } \\
\text { leitura, navegação, busca e compartilhamento }\end{array}$ & $\begin{array}{l}\text { Os elementos de interação possuem destaque visual } \\
\text { ou chamada textual como "What's happening" que } \\
\text { incentivam a ação do usuário. }\end{array}$ \\
\hline 7 & $\begin{array}{l}\text { Entrada facilitada para contribuições simples (por ex.: } \\
\text { sem login) }\end{array}$ & $\begin{array}{l}\text { O newsfeed oferece um campo rápido para } \\
\text { contribuições simples e comentários. }\end{array}$ \\
\hline 8 & $\begin{array}{l}\text { Interface ampla, permitindo contribuições mais longas } \\
\text { e frequentes }\end{array}$ & $\begin{array}{l}\text { Para contribuições maiores, há blogs e fóruns } \\
\text { de discussão. }\end{array}$ \\
\hline 9 & $\begin{array}{l}\text { Visibilidade para as contribuições dos usuários, } \\
\text { frequência de visualizações ao longo do tempo }\end{array}$ & $\begin{array}{l}\text { Todas as contribuições aparecem no newsfeed, mas } \\
\text { não há diferenciação para contribuições relevantes. }\end{array}$ \\
\hline 10 & $\begin{array}{l}\text { Visibilidade das avaliações e comentários dos membros } \\
\text { da comunidade }\end{array}$ & $\begin{array}{l}\text { As contribuições podem ser avaliadas com likes e } \\
\text { comentários. Em alguns casos, como fotos e blogs } \\
\text { há uma opção extra de avaliação em uma escala de } \\
\text { cinco estrelas. }\end{array}$ \\
\hline 11 & $\begin{array}{l}\text { Ferramentas para desfazer práticas de vandalismo, } \\
\text { limitar usuários mal-intencionados, controlar a } \\
\text { pornografia }\end{array}$ & Não há link ou página específica para denúncias. \\
\hline 12 & $\begin{array}{l}\text { Formas de localizar indivíduos relevantes e } \\
\text { competentes para formar colaborações }\end{array}$ & $\begin{array}{l}\text { Há destaque apenas para os administradores dos } \\
\text { grupos e os criadores de tópicos em fóruns. }\end{array}$ \\
\hline 13 & $\begin{array}{l}\text { Ferramentas colaborativas: comunicação entre grupos, } \\
\text { agenda de projetos, tarefas, compartilhamento de } \\
\text { trabalhos, assistência }\end{array}$ & $\begin{array}{l}\text { Os diferentes recursos como grupos, blogs, fóruns e } \\
\text { chat possibilitam a fácil comunicação entre membros. }\end{array}$ \\
\hline 14 & $\begin{array}{l}\text { Reconhecimento público e premiações, por ex.: } \\
\text { autoria, citações, links, agradecimentos }\end{array}$ & $\begin{array}{l}\text { Não há na interface padrão forma de reconhecimento } \\
\text { público, ranking ou premiação de usuários. }\end{array}$ \\
\hline 15 & $\begin{array}{l}\text { Formas de resolver diferenças (por ex. votações), } \\
\text { mediar disputas e lidar com colaboradores inúteis } \\
\text { (que atrapalham) }\end{array}$ & $\begin{array}{l}\text { Não há campo de denúncia, mas é possível mediar } \\
\text { conflitos e discussões em fóruns ou com comentários } \\
\text { no newsfeed. }\end{array}$ \\
\hline 16 & $\begin{array}{l}\text { Líderes recebem mais visibilidade e seus esforços } \\
\text { são destacados, às vezes com narrativas históricas, } \\
\text { homenagens ou prêmios }\end{array}$ & $\begin{array}{l}\text { Não há destaque para usuários líderes ou ranking } \\
\text { de contribuições. }\end{array}$ \\
\hline 17 & $\begin{array}{l}\text { Líderes recebem poderes especiais, por ex. para } \\
\text { promover pautas, utilizar recursos, ou limitar usuários } \\
\text { mal-intencionados }\end{array}$ & $\begin{array}{l}\text { Líderes podem ser administradores de grupos, mas } \\
\text { isso não garante o poder de edição ou moderação } \\
\text { do conteúdo. }\end{array}$ \\
\hline 18 & $\begin{array}{l}\text { Esforços de orientação são visivelmente enaltecidos, } \\
\text { por exemplo, com comentários de orientandos }\end{array}$ & $\begin{array}{l}\text { Não há campo específico para destacar esforços dos } \\
\text { líderes, como depoimentos, por exemplo. }\end{array}$ \\
\hline
\end{tabular}




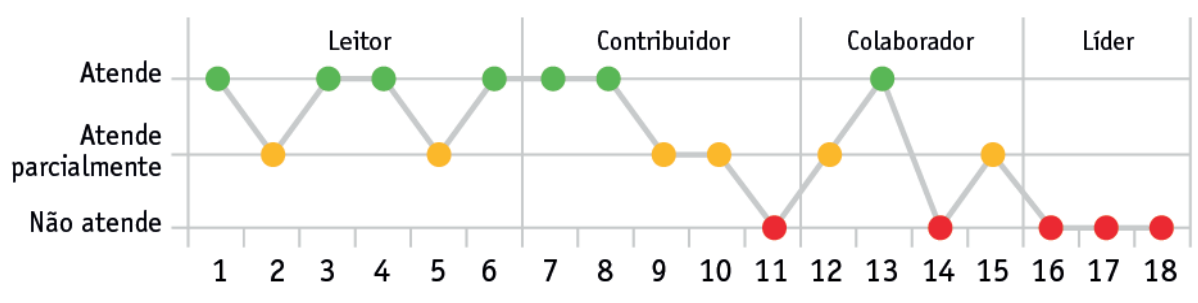

Figura 7 Gráfico da análise dos fatores de usabilidade

O gráfico resultante da análise apresenta inicialmente um grande foco no usuário leitor e nenhuma estratégia de interface voltada para atividade de liderança. De acordo com framework de Preece e Schneiderman (2009), a interface deve prover essa evolução. Observa-se que enquanto leitor, o usuário poderá encontrar dificuldade em encontrar conteúdos relevantes no newsfeed, pois se houver atualizações frequentes, a tendência é que as publicações sigam a ordem cronológica, sem opção de destaque. Por outro lado, em algumas funcionalidades como o fórum, é possível fixar um tópico no topo da lista (sticky) de modo que os usuários rapidamente o encontrem (Figura 8). O blog também oferece opção similar ao filtrar os posts com melhor avaliação ou os mais discutidos (Figura 9).

\begin{tabular}{|c|c|c|c|c|}
\hline & Topic & Replies & Views & Last Reply \\
\hline \begin{tabular}{|l|} 
NEW \\
LOCKED \\
STICYY \\
\end{tabular} & Forum rules & - & 30 & Last Reply by Mike Mar 20 '13 \\
\hline NEW & What's up? & - & 33 & Last Reply by Mike Mar 20 ' 13 \\
\hline
\end{tabular}

Figura 8 Etiquetas que sinalizam tópicos novos, fixos no topo da lista ou bloqueados (Fonte: Demonstração Oxwall (2013))

\section{USER BLOGS}

(1) LATEST TOP RATED MOST DISCUSSED BROWSE BY TAG

Figura 9 Filtro de posts no recurso de blog. (Fonte: Demonstração Oxwall (2013))

Em relação à acessibilidade, um teste com plugin Accessibility Developer Tools (снRоме, 2013), desenvolvido pelo Google, revelou que algumas imagens e links da interface padrão não apresentam texto alternativo, o que prejudica a navegação por meio de softwares leitores de tela utilizados por usuários cegos e de baixa visão. Além disso, a inserção do texto alternativo não é requisito quando o usuário publica uma imagem, visto que o campo não existe na caixa de inserção deste tipo de mídia (Figura 10). 


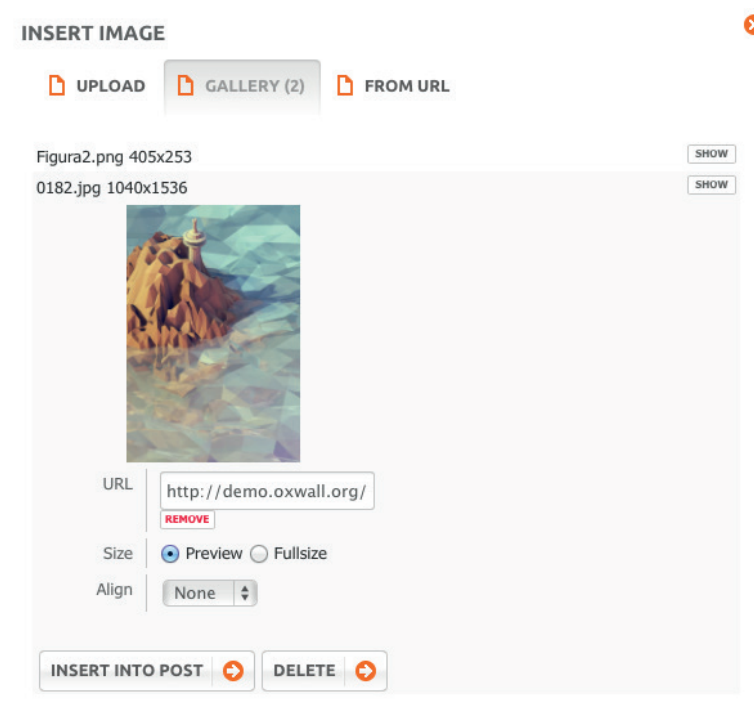

Figura 10 Caixa de inserção de imagem sem o campo para texto alternativo (Fonte: Demonstração Oxwall (2013))

A análise dos fatores que propiciam a contribuição teve resultados diferentes do primeiro grupo de itens. Neste caso, dois fatores são atendidos parcialmente e um não é atendido. Para aprimorar a navegação desse tipo de usuário, deve-se ampliar a visibilidade das contribuições, indicando as mais relevantes e em maior quantidade. Redes sociais massivas como o Facebook vem trabalhando em algoritmos para priorização automática de conteúdo de acordo com os interesses dos usuários (GLOBO, 2014). Além disso, devem ser implementadas ferramentas de controle de publicações indevidas e mal-intencionadas, de modo que os membros possam denunciar casos que não estejam de acordo com as políticas de uso da rede.

O usuário que atingir o nível de colaborador, poderá encontrar alguns obstáculos, apesar da interface oferecer diversas ferramentas colaborativas. De acordo com framework, é preciso também promover espaços para o reconhecimento público e premiações dos usuários, criando rankings e painéis que destaquem os esforços dos colaboradores. Ainda para colaboração, identificou-se que não há formas pré-estabelecidas de resolver diferenças e mediar disputas, como enquetes e votações, contando-se apenas com tópicos de discussão no fórum. Uma das características que impulsiona essa lacuna é que a interface não diferencia usuários iniciantes de colaboradores e líderes. Assim, o usuário não sabe a quem e como recorrer caso necessite de moderação na rede.

Observa-se também que a interface não provê elementos que impulsionem a liderança. Conforme já apresentado, não há, na interface, uma forma de destacar os usuários que possuem um status diferenciado em suas comunidades. Membros que são referência em algum conteúdo e que poderiam incentivar discussões e exercer a moderação não são reconhecidos visualmente. Excetuando-se o caso da funcionalidade de grupos, o administrador até é apresentado, mas 
ele não possui privilégios de edição ou controle de conteúdo. Esforços de orientação recebem o mesmo tratamento de publicações comuns, via comentários.

Por fim, tratando-se da composição visual, pode-se afirmar que a interface em blocos organiza a informação, setorizando recursos e assuntos específicos. Além disso, observa-se que há affordance (NORMAN, 2006) em grande parte dos elementos de interação. Os botões em relevo contrastam do fundo branco e os campos de inserção de conteúdo sugerem a escrita, conforme o exemplo apontado na Figura 11. A disposição deste campo na interface também colabora com a interação ao estar no topo das atividades, no layout da página pessoal.

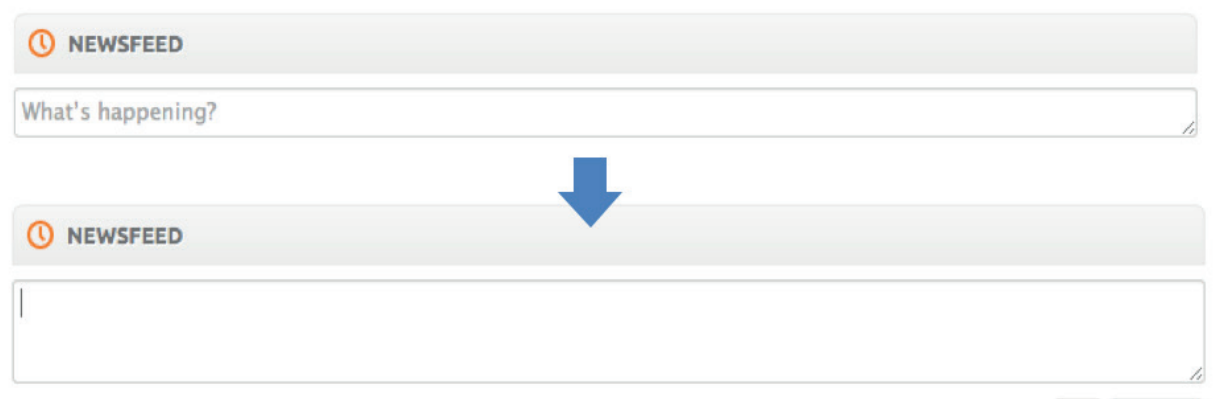

Figura 11 Caixa de inserção de conteúdo rápido no newsfeed (Fonte: Demonstração Oxwall (2013))

O campo de escrita do newsfeed, contudo, limita-se a inserção de texto e imagem. Não é possível, na interface padrão do Oxwall, criar um evento, tópico de discussão ou post de blog a partir da página inicial. Todavia, em outros templates para Oxwall disponíveis na comunidade, como o "Crayon", é possível observar um bloco de acesso rápido à inserção de conteúdo (Figura 12), visível em todas as páginas da rede.

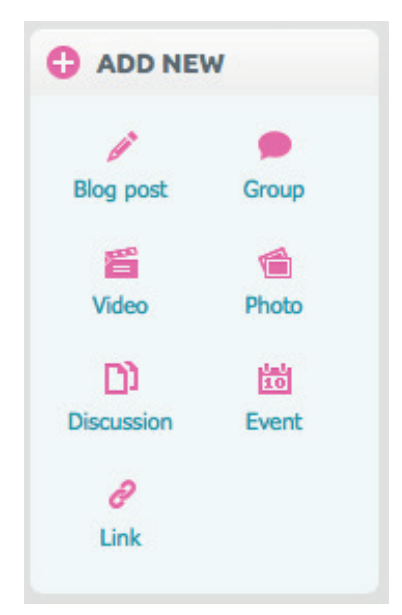

Figura 12 CBloco de acesso rápido à inserção de conteúdo no template Crayon (Fonte: Demonstração Oxwall, template Crayon (2013)) 
Assim, apesar da facilidade de navegação na interface padrão, observa-se que pequenas alterações podem influenciar ainda mais a contribuição dos usuários.

\section{Considerações Finais}

Este artigo analisou a interface do Oxwall, um software livre para construção de redes sociais. A análise baseada no framework Readerto-Leader apontou algumas lacunas que podem prejudicar o progresso dos usuários na rede.

Apesar de apresentar espaços para interação, promovendo a contribuição e a colaboração, a interface padrão carece de espaços que promovam usuários e publicações mais relevantes, gerando reconhecimento e status para os membros que dispendem esforços na construção do conteúdo e da rede. Além disso, apesar de apresentar a entrada facilitada para contribuições rápidas, observa-se que é possível facilitar ainda mais a contribuição tornando as possibilidades de interação mais visíveis, a exemplo do template Crayon, disponível para o Oxwall.

Em relação ao framework, nota-se que os autores se preocuparam em fornecer diretrizes gerais para promover o envolvimento, focando em elementos que pudessem incentivar a inserção de conteúdo pelo usuário. Durante a avaliação observou-se que cada uma das diretrizes envolve ainda uma série de indicadores não apresentados no framework, envolvendo elementos básicos de design e usabilidade. Essa falta, contudo, não reduz a importância dos critérios utilizados, visto que carregam uma percepção diferenciada da interface como mídia que promove a colaboração do usuário.

Uma rede social temática, assim como outra rede social, é um ambiente vivo, hiperconectado, que se alimenta das contribuições dos seus usuários. A geração de conteúdo em uma rede depende de seus membros, pois se todos fossem leitores, em algum momento não haveria mais informações relevantes e a rede estaria fadada ao insucesso.

A análise presente neste artigo considerou as funcionalidades básicas da interface padrão do Oxwall na língua inglesa. Contudo, cabe ressaltar que a plataforma possui dezenas de plugins extras que podem contribuir ou até resolver os problemas apontados. Próximos estudos poderão abordar essas ferramentas adicionais, assim como realizar testes de usabilidade com usuários e tarefas relacionadas aos diferentes perfis de uso. 


\section{Agradecimento}

Ao CNPq e CAPES, por terem possibilitado e financiado parcialmente esta pesquisa.

\section{Referências}

ALBORS, J. ; RAMOS, J. C.; HERVAS, J. L. (2008). New learning network paradigms: Communities of objectives, crowdsourcing, wikis and open source. International Journal of Information Management, vol. 28: 194-202.

BOYD, D. M.; ELLISON, N. B. (2008) Social network sites: Definition, history, and scholarship. Journal of Computer-Mediated Communication, vol. 13, n. 1. p. 210-230.

CHRoмe. Accessibility Developer Tool. Disponível em: < https:// chrome.google.com/webstore/detail/accessibility-developer-t/ fpkknkljclfencbdbgkenhalefipecmb> Acesso em 11 jul 2013.

CMS CRITIC. List of Social Network Site and Platforms. Social Network Software. Disponível em: <http://www.cmscritic.com/dir/social-network-software/ open-source/php/>. Acesso em 10 jul 2014.

CRESSWELL, J. W. (2003). Research design: Qualitative, quantitative, and mixed method approaches. 2 ed., Thousand Oaks, CA: Sage.

CRITICS' CHOICE CMS AWARDs. Past Winners. Disponível em: <http://awards. cmscritic.com/past-winners/>. Acesso em 11 jul 2013.

KAPLAN, A. M.; HAENLEIN, M., (2010). Users of the world, unite! The challenges and opportunities of social media, Business Horizons, vol. 53, n. 1:59- 68 . GLOво. (2014) Facebook novamente altera algoritmo do 'News Feed', 22 jan. $O$ Globo - Tecnologia. Disponível em <http://oglobo.globo.com/sociedade/ tecnologia/facebook-novamente-altera-algoritmo-do-news-feed-11372068>. Acesso em 10 jul 2014.

HOWARD, T. (2010). Design to Thrive: Creating Social Networks and Online Communities that Last. Burlington: Morgan Kaufmann.

Iворе. (2013). Número de usuários de redes sociais ultrapassa 46 milhões de brasileiros. Disponível em <http://www.ibope.com.br/pt-br/noticias/ Paginas/Numero-de-usuarios-de-redes-sociais-ultrapassa-46-milhoes-debrasileiros.aspx>. Acesso em 11 jul 2013.

ISMAIL, к. (2013) 8 Great Social Networking CMS. CMS Critic, 27 mai. Disponível em: <http://www.cmscritic.com/8-great-social-networking-cms>. Acesso em 10 jul. 2014 .

NORMAn, D. A. (2006). O Design do Dia-a-Dia. Rio de Janeiro: Rocco.

oxwALl. o - PHP Social Networking Software. Disponível em <http://www. oxwall.org>. Acessado em 11 jul 2013.

PALAZZO, L. A. M.; ULBRICHT, V. R.; VANZIN, T. ; FLORES, A.R.B; LINDNER, L. H. Redes Sociais Temáticas apoiando AVEA - I. In: BUSARELLO, R.I.; BIEGING, P.; ULBRICHT, V.R. (2013). (Org.). Mídia e Educação: novos olhares para a aprendizagem sem fronteiras. 1 ed. São Paulo: Pimenta Cultural, v. 1:118-130. 
PREECE, J.; SHNEIDERMAN, B. (2009). The Reader-to-Leader Framework:

Motivating Technology-Mediated Social Participation, AIS Transactions on

Human-Computer Interaction, v. 1, n.1:13-32.

PREECE, J., ROGERS, I., SHARP, H. (2013). Design de Interação - além da Interação

homem-computador. Porto Alegre: Bookman.

WENGER, E., (1998). Communities of Practice: Learning, Meaning, and Identity.

Cambridge: University Press, USA.

. (2010). Communities of practice and social learning systems. Organization, v.

7, n. 2: 225-246.

ZHAN, M. (2010). Social Netork Analysis: History, Concepts, and Research. In:

FURHT, B, 2010. Handbook of Social Networks Technologies and Applications.

New York: Springer-Verlag:3-21

\section{Sobre os autores}

\section{Luís Henrique Lindner}

$<$ luishenrique87@gmail.com>

Mestrando em Engenharia e Gestão do Conhecimento, Universidade Federal de Santa Catarina. MBA em Marketing Estratégico na UNIVALI, possui graduação em Design pela UFSC. Tem experiência nas áreas de Design, Educação e Marketing e pesquisa redes sociais e visualização do conhecimento.

\section{Vania Ribas Ulbricht}

<ulbricht@floripa.com.br>

Dra. em Engenharia de Produção pela Universidade Federal de Santa Catarina. É professora colaboradora da Universidade Federal do Paraná no Programa de Pós- Graduação em Design. Pesquisadora da Université Paris 1 (Panthéon-Sorbonne) e presta serviço voluntário no PPEGC da UFSC. Foi bolsista em Produtividade e Desenvolvimento Tecnológico e Extensão Inovadora de 2009 a 2013, DT/CNPq. Atualmente é Bolsista de Desenvolvimento Tecnológico Industrial do CNPq - Nível A

\section{Luiz Antônio Moro Palazzo}

$<$ luiz.palazzo@gmail.com>

Dr. em Ciências da Computação pela Universidade Federal do Rio Grande do Sul, possui ampla experiência em Sistemas de Informação, atuando principalmente nos seguintes temas: Web Semântica e Ontologias, Hipermídia Adaptativa, Redes Sociais, Inteligência Artificial, Programação em Lógica, Educação na Web e Informática na Educação.

Artigo recebido em 02 abr. 2014, aprovado em 29 jul. 2014. 
Lindner L. H., Ulbricht V. R., Palazzo L. A. M. | Análise da interface padrão do Oxwall como plataforma de rede social 